\title{
Review of evidence for immune evasion and persistent infection in Lyme disease
}

This article was published in the following Dove Press journal:

International Journal of General Medicine

22 April 2013

Number of times this article has been viewed

\section{Keith Berndtson}

Park Ridge MultiMed, Park Ridge, IL, USA
Correspondence: Keith Berndtson Park Ridge MultiMed, 15 N Prospect Ave, Park Ridge, IL 60068, USA

Tel + I 8472329800

Fax + I 8472329810

Email keith@parkridgemd.com
Abstract: Is chronic illness in patients with Lyme disease caused by persistent infection? Three decades of basic and clinical research have yet to produce a definitive answer to this question. This review describes known and suspected mechanisms by which spirochetes of the Borrelia genus evade host immune defenses and survive antibiotic challenge. Accumulating evidence indicates that Lyme disease spirochetes are adapted to persist in immune competent hosts, and that they are able to remain infective despite aggressive antibiotic challenge. Advancing understanding of the survival mechanisms of the Lyme disease spirochete carry noteworthy implications for ongoing research and clinical practice.

Keywords: Lyme disease, Borrelia, biofilm, bacterial persistence, antibiotic tolerance

\section{Introduction}

Lyme disease (LD) is a tick-borne illness caused by the spirochete Borrelia burgdorferi $(B b)$. In North America, virulent strains of $B b$ are transmitted to humans and other animals by the deer tick, Ixodes scapularis. In addition to transmitting $B b$ into various animal hosts, during a feeding session deer ticks can also transmit strains of Anaplasma, Bartonella, Ehrlichia, or Babesia in combination with $\mathrm{Bb}{ }^{1,2}$

The illnesses resulting from such transmissions can produce polymicrobial infections whose interaction effects pose serious challenges for researchers investigating the etiopathogenesis of tick-borne illnesses, and for clinicians who would diagnose and treat the illness dynamics caused by them. Some aspects of the morbidity seen in posttreatment Lyme cases are likely caused by postinfectious immune processes, but this line of research is not the subject of this review. This paper reviews the known and suspected mechanisms by which $B b$ evades the immune systems of animal hosts. The review sections cover notable capabilities of the $B b$ genome, which encodes $B b$ 's ability to:

- Exploit tick salivary proteins to delay early host immune responses.

- Deceive alternative complement pathways by masking surface antigens.

- Usurp the host's plasminogen activating system.

- Continuously vary its surface antigens to frustrate humoral immune responses.

- Translocate using uniquely agile motility skills.

- Use chemotactic and niche-seeking traits to evade host immune traffic.

- Engage in quorum sensing and in biofilm-like behavior.

- Upgrade its genetic code through horizontal gene transfer (HGT).

- Assume atypical morphologies that differ from its spirochetal form. 
- Potentially form persister cells able to tolerate antibiotic challenge (thus far unproven).

The review also explores how these mechanisms might cause persistent symptoms despite standard antibiotic therapy, examines three studies that provide credible evidence for $B b$ persistence despite antibiotic challenge, and identifies implications for ongoing research and for medical practice.

The Infectious Disease Society of America (IDSA) has published guidelines on the diagnosis and treatment of LD. ${ }^{3}$ Other publications call into question the adequacy of IDSA's standards for the diagnosis and treatment of LD. ${ }^{4-6}$ This review explores developments at the intersections of LD research that might lead us toward a resolution of a controversy that frustrates many patients with LD and continues to divide members of the medical profession. ${ }^{7-12}$

Steere et $\mathrm{al}^{13}$ authored the first definitive account of LD in 1977, describing a condition that was initially thought to be an outbreak of juvenile rheumatoid arthritis in and around the town of Lyme, Connecticut. By 1982, Burgdorfer et a ${ }^{14}$ had determined the cause of the syndrome - a previously unknown spirochete that today is known as $B b$. In 1983, Steere et $\mathrm{al}^{15}$ presented the authoritative account marking $B b$ as the cause of LD.

In 1988, Asbrink and Hovmark ${ }^{16}$ conceived of untreated LD as having three phases. Phase 1 represented early, localized infection, the hallmark of which was erythema migrans (EM) and its variations. Phase 1 included fever, muscle aches, headache, nausea, and fatigue. Phase 2 witnessed early dissemination of the infection with worsening of malaise and fatigue, as well as the appearance of new cardiac and arthritic signs and symptoms including atrioventricular heart block, myocarditis, migratory joint pains, and synovitis. Phase 3 saw late dissemination with the appearance of polyneuropathy, neurocognitive and neuropsychiatric abnormalities, and meningitis, as well as chronic arthritis and debilitating fatigue. ${ }^{16}$

In 1989, Steere $^{17}$ defined LD as a diagnosable, fully treatable infectious disease capable of producing persistent signs and symptoms. In his review, the author noted that viable spirochetes were sometimes recovered from joint tissue in phase 3 patients, suggesting that LD could become a persistent infection, but he speculated that $B b$ "may trigger an immune response with autoreactive features that continues for some time after the organism has been killed." ${ }^{17}$ This marked the formal onset of a debate around a question that persists to this day: are persistent signs and symptoms in LD caused by persistent infection?
As a community-based general medicine physician, I am called upon from time to time to assist patients who definitely have or may have LD. I understand that doctors are divided on how to go about providing such assistance, and that the uncertainty has a tendency to paralyze the way doctors care for such patients. I chose to conduct my own review of the peer-reviewed literature to see how the evidence should guide a physician in my position. To determine if LD is capable of evolving into a persistent infection associated with inflammation, I reviewed published evidence on the immune evasiveness of $B b$.

\section{How Bb evades the immune systems of animal hosts}

Research is clarifying traits by which $B b$ evades host immune systems and survives antibiotic challenge. Highlights of this research are described in the sections that follow.

\section{A flexibly adaptive genome}

The $B b$ genome is relatively small. In 1997, Fraser et al ${ }^{18}$ reported the genomic sequence for the $\mathrm{B} 31$ strain of $B b$. The linear chromosome contains roughly 900 genes encoding proteins for replication, transcription, translation, energy metabolism, and transmembrane transport, but no genes for cellular biosynthesis of amino acids, fatty acids, enzyme cofactors, or nucleotides.

This limited metabolic capacity is overcome with help from genes found on nine linear and 12 circular plasmids, and with help from metabolic pathways in the host. The plasmids together function as a portable incubator for genetic innovation that allows $B b$ to accomplish immune evasion feats not witnessed elsewhere in the bacterial kingdom.

De Silva and Fikrig ${ }^{19}$ described the differential gene expression patterns seen as $B b$ moves from an arthropod host into a mammalian host. As a feeding tick becomes engorged, $\mathrm{Bb}$ ceases production of outer-surface proteins (Osp)A and $\mathrm{OspB}$ and begins expressing highly immunogenic OspC. ${ }^{20}$ OspA and OspB are the two major lipoprotein components of spirochete's outer membrane but they play a small infectivity role, if any. Their expression commonly returns during the late dissemination phase as an indicator of late infection. OspA induces a proinflammatory host response during late infection, suggesting that it may be downregulated during the onset of infection to avoid inciting an early inflammatory response.

De Silva and Fikrig ${ }^{19}$ subsequently found that when infected ticks fed upon OspA-immunized mice, the antibodies the mice made against OspA found their way to the tick's midgut and killed $B b$ in that location, preventing 
transmission of the infection to a new host. ${ }^{21}$ OspA thus became the first vaccine molecule of its kind - a protein that stimulates antibody production to protect hosts by blocking the vector's ability to transmit the pathogen.

Two pharmaceutical companies took up the challenge of bringing the OspA vaccine to market. One pulled out early; the other received a Federal Drug Administration license for permissive use of the vaccine in 1998, but then withdrew the product from the market in 2001 in the face of regulatory roadblocks and public health concerns about potentially serious unanticipated side effects in some patients. ${ }^{22}$ It remains unclear what kind of vaccine approach can safely and reliably outsmart $B b$ 's flexibly adaptive genome.

\section{The commandeering of arthropod salivary proteins}

Ramamoorthi et $\mathrm{al}^{23}$ have shown that $B b$ binds a tick salivary protein (Salp15) on its way from the tick's midgut to a new animal host. $B b$ OspC binds to Salp15 while in the salivary gland of the feeding tick. Once inside its new animal host, the OspC-Salp 15 complex protects $B b$ from antibody-mediated killing for an undetermined period of time, buying time for other virulence factors to gain traction.

Tick salivary proteins have been shown to inhibit the activation and proliferation of CD4+ T-cells by binding to the CD4 receptor. ${ }^{24,25}$ They have also been found to inhibit natural killer cells, ${ }^{26}$ dendritic cells, ${ }^{27}$ macrophages, ${ }^{28}$ and neutrophils. ${ }^{29}$ Hannier et al ${ }^{30}$ detected an $18 \mathrm{kDa}$ protein in the saliva of Ixodes ricinus that inhibits the ability of OspA and OspC to stimulate B-cell proliferation. They found that the action of this B-cell inhibitory protein may aid transmission by preventing B-cell activation. B-cell inhibitory protein halts B-cell proliferation during the G1 phase of the cell cycle. The effect seems to be localized to the feeding site and its activity falls off within 24 hours in vitro. The result could be lowered inflammation at the feeding site that results in misleading antibody information when screening for $B b$ infection.

\section{Usurpation of the new host's plasminogen activation system}

Önder et $\mathrm{al}^{31}$ showed that OspC forms a plasminogen receptor on the surface of $B b$. By recruiting plasminogen to this receptor, $B b$ is able to co-opt the action of plasmin for its own purposes. Plasmin enzymatically digests fibrin and large glycoproteins, which can create a path for $B b$ from the circulation to the extracellular matrix (ECM), where it can escape exposure to immune cells and antibodies patrolling lymph and vascular systems.
Lagal et $\mathrm{a}^{32}$ used $B b$ sensu stricto strains to assess variable levels of invasiveness in mice, and found that the invasiveness of $B b$ in mice depends on genomic variations in OspC. Grab et $\mathrm{al}^{33}$ used an in vitro model to identify plasminassociated mechanisms by which $B b$ might traverse the blood-brain barrier and invade the central nervous system.

\section{Deception of the new host's alternative complement pathway}

The three pathways of the complement system play a primary role in the innate response to pathogens. These pathways consist of circulating protein precursors that, when cleaved, trigger cascades that produce membrane attack complexes (MACs). MACs form transmembrane channels that can effectively lyse and kill microbial cells.

The classic pathway is triggered when complement protein $\mathrm{Cq} 1$ binds to immunoglobulin (Ig)M- or IgG-antigen complexes. ${ }^{34}$ The alternative complement pathway is triggered when complement protein $\mathrm{C} 3 \mathrm{~b}$ binds to a pathogen surface, unless factor $\mathrm{H}$ is present on the cell surface, in which case that cell will escape destruction by MACs. ${ }^{35}$ The lectin pathway is triggered when mannin-binding lectin or ficolins bind to glycosylated molecular patterns on a pathogen's surface. ${ }^{36}$ This activates mannin-binding lectin-associated serine proteases. Mannin-binding lectin-associated serine proteases then amplify both the classical and alternative complement cascades.

Schuijt et $\mathrm{a}^{137}$ found that Salp15 from Ixodes scapularis and Ixodes ricinus inhibits complement-mediated killing in vitro. Henningson et $\mathrm{al}^{38}$ found cerebrospinal fluid (CSF) evidence for complement activation via the classical pathway in patients with neuroborreliosis. Such findings suggest that $B b$ activates, but is able to avoid being killed by, the host's complement pathways - a capacity that would buy spirochetes time to find immune privileged tissue niches in the early dissemination phase.

Alitalo et $\mathrm{al}^{39}$ demonstrated that serum-resistant strains of $B b$ are able to promote factor 1-mediated cleavage of $\mathrm{C} 3 \mathrm{~b}$ by surface-binding the complement regulating factors, factor $\mathrm{H}$ and factor $\mathrm{H}$-like protein 1. Factor $\mathrm{H}$ functions like a "hall pass" that allows $B b$ to escape destruction by alternative complement pathways. Alitalo et $\mathrm{al}^{40}$ subsequently found that factor $\mathrm{H}$ was binding to $\mathrm{OspE}$, and that OspE production depended on the inducible expression of OspE variants by multiple plasmids. They concluded that OspE functions as a complement evasion molecule.

Hefty et $\mathrm{al}^{41}$ showed that OspE expression is triggered when signals from a blood meal reach the tick's midgut. 
They also reported striking heterogeneity in $B b$ populations during transmission and infection. This diversity was the result of temporal changes in antigen expression, but also by modulation of surface lipoproteins during infection. Signals from the blood meal prepare $B b$ to evade the new host's alternative complement system by finding a factor $\mathrm{H}$ badge that, when fastened to OspE, will cause the host to mistake $\mathrm{Bb}$ for one of its own cells.

\section{Use of antigenic variation to frustrate host humoral immune responses}

Antigenic variation is a common mechanism that helps pathogens evade immune recognition by use of recombinational shuffling of genetic information to produce continually changing surface epitopes. ${ }^{42}$ In $B b$, this effect is produced by means of a variable major protein-like sequence system at the locus that expresses the surface-exposed lipoprotein, VlsE. Zhang et $\mathrm{al}^{43}$ localized this mechanism to the $B b$ linear plasmid $1 \mathrm{p} 28-1$, a finding corroborated by Kawabata et al. ${ }^{44}$

Norris described the underlying interchangeable cassette mechanism for the recombinational shuffling that allows $B b$ to vary surface antigen epitopes. ${ }^{45} \mathrm{~A}$ gene cassette is a modular deoxyribonucleic acid (DNA) sequence encoding one or more genes for a single biochemical function. The VlsE central cassette is contiguous to a series of 15 homologous silent cassettes that encode different amino acids in each of six variable lipoprotein regions. Upon entering an animal host, segments of the silent cassettes continuously replace segments of the VlsE central (expression) cassette, producing nonstop variations in VlsE amino acid sequences. Antigenic variation hampers host humoral responses to infection by forcing the host immune system to contend with antigen epitopes that appear just long enough to incite a humoral response before they vanish, leaving B cells confused.

Hastey et $\mathrm{al}^{46}$ investigated the humoral response to $\mathrm{Bb}$ with the goal of elucidating how $B b$ causes host immune responses to fail. They found an early $\mathrm{T}$ cell-independent accumulation of B cells within lymph nodes, followed by a second phase showing short-lived germinal centers without clearly demarcated $\mathrm{T}$ and $\mathrm{B}$ cell zones. This phase failed to produce long-lived bone marrow plasma cells, but they did find a slow accumulation of long-lived antibody-secreting plasma cells in bone marrow, suggesting a strong but sluggish and ineffective serum antibody response.

These findings suggest that antigenic variation mediates $B b$ 's ability to interfere with humoral response kinetics and quality. The net effect for the host is production of B-cells and plasma cells whose antibodies seek surface epitopes that are not easy to find, and whose clonal populations accumulate in lymph nodes and bone marrow where one can imagine crosstalk aimed at figuring out which way the suspects went.

Dresser et $\mathrm{al}^{47}$ identified the first factor known to be essential to antigenic switching in $B b$ : the branch migrase known as ruvA. Lin et $\mathrm{al}^{48}$ independently confirmed a central role for ruvA in VlsE recombination in $B b$, and showed that in mice, ruvA and ruvB mutants are associated with reduced $B b$ infectivity and increased clearance of $B b$ with the help of antibiotics. In immune-deficient mice (severe combined immunodeficiency [SCID] strain), Lin et $\mathrm{al}^{48}$ found that $B b$ retained infectivity despite ruvA inactivation, suggesting that the sicker the host's immune system, the less $B b$ needs to rely on antigenic switching. Host immune competence is not the only variable here. Work by Lawrenz et $\mathrm{al}^{49}$ and by Bankhead and Chaconas ${ }^{50}$ demonstrated that to be infective, $B b$ requires variation-competent VlsE functionality.

\section{Advanced motility capabilities}

Roughly $6 \%$ of the $B b$ linear chromosome is devoted to motility and chemotactic functions, which is higher than usual for bacteria. ${ }^{18}$ Compared to other bacteria, $B b$ devotes more of its genomic resources to the production of lipoproteins, many of which are antigenic. ${ }^{51}$ Norris $^{52}$ had explored how motility genetics influence the virulence in Borrelia strains. Using a cryoelectron tomography technique, Liu et $\mathrm{al}^{53}$ ran what are in essence microscopic computed tomography scans of the B31 strain of $B b$ yielding threedimensional ultrastructural data on the rotor mechanism that propels flagellar motion in this spirochete. The flagellae have a motor-hook-filament structure similar to that seen in other bacteria, ${ }^{54}$ but the filaments form uniquely designed ribbons within the periplasmic space, a feature not seen in prokaryotes outside the spirochaetes phylum. ${ }^{55}$

$B b$ motility is designed for swimming through liquid environments such as blood, lymph, and CSF, and for squirming and tunneling through viscoelastic gel environments like the ECM and other connective tissues. Kimsey and Spielman ${ }^{56}$ described an increase in gyration in the presence of methylcellulose or hyaluronic acid, suggesting that ECM chemoattractants can trigger changes in $\mathrm{Bb}$ flagellar coordination.

Charon et $\mathrm{al}^{57}$ point out that the motility paradigms of other flagellated bacteria do not apply to $B b$. The motility capabilities of $B b$ are somewhat unique in that they contain twin motors, one at the front and the other at the rear of the protoplasmic cylinder. These motors control the flex and 
rotation of the flagellar ribbons in the periplasmic space. In the center location of this space, the ribbons overlap, allowing for interactions between front and rear motors. This design creates four swim configurations based on clockwise versus counter-clockwise rotations of the front and rear motors.

Moriarty et $\mathrm{al}^{58}$ were the first to publish real-time highresolution video of host $-B b$ interactions in living mice. ${ }^{58}$ Using intravital microscopy and four-dimensional spinning disk confocal microscopy methods, they studied the dynamics of $B b$ endothelial cell (EC) adherence and dissemination out of the vasculature in living mice. They noted that infectious spirochetes initially associated with capillaries, postcapillary venules, and larger veins, but not with arterioles, perhaps due to the higher shear forces on the arterial side. They described transient interactions between $B b$ and EC surfaces, followed by a dragging or crawling motion that may represent the spirochete searching for a suitable location to form a stationary adhesion. Stationary adhesions typically occurred at an EC junction, and formation was sometimes associated with a probing-type behavior. Spirochetes would then tend to remain fully or partially embedded in EC regions that expressed platelet EC adhesion molecule-1.

Some spirochetes would transmigrate through the vessel wall, typically at EC junctions, and escape into the surrounding ECM in a process that averaged 10.8 minutes. They could move in either direction as quickly as $624 \mu \mathrm{m} /$ minute. Moriarty et a ${ }^{58}$ note, "the great speed of these bacteria in situ might thus have accounted for our difficulty in capturing the initial and final stages of extravasation" and that "the speed of the final escape phase [yielded images] in which spirochetes appeared to burst away from the vessel."

Advanced imaging techniques make it clear that $B b$ is no ordinary bacterium. It has motility prowess heretofore unseen in the microbial world. It is built to infiltrate, evade, and persist.

\section{Evasive chemotaxis and niche-seeking behaviors}

$\mathrm{Bb}$ contains the most redundant set of chemotaxis-related genes found among eubacteria. ${ }^{18}$ Once inside an animal host, $B b$ uses chemoreceptor arrays at its cell poles to follow chemoattractant trails to reach specific host cells or tissue compartments. ${ }^{59,60}$ Sze et $\mathrm{al}^{61}$ have shown that when $B b$ becomes nonchemotactic to attractants, it abrogates infectivity even when the host is immunodeficient. Chemotaxis and adherence are often the first step in an infectivity sequence by pathogens. Once a favorable destination is reached, $B b$ uses adhesins to bind to target molecules including glycosaminoglycans (GAGs), decorin, and fibronectin. ${ }^{62-64}$

The ECM is a mesh-like superstructure that consists of interstitial tissue, basement membranes, collagen, and polysaccharide gels, and it appears to be $B b$ 's most favored destination in mammalian hosts. The ECM is rich with GAGs, decorin, and fibronectin. GAGs are long unbranched polysaccharides found on cell surfaces and within the ECM. Fibronectin is a glycoprotein that binds to cellular integrins, activating cytoskeletal changes that allow the cell to deform and move through dense weaves of collagen.

Initial charge interactions likely make GAGs and proteoglycans (PGs) the first cell surface molecules recognized by $B b$. When covalently bound to protein cores, GAGs become PGs. PGs are some of the largest and most complex molecular structures found in mammalian cells and the ECM. ${ }^{65}$ The PGs found in epithelial, vascular, muscle, and peripheral nerve basement membranes mostly contain GAG side chains of heparan sulfate or chondroitin sulfate. ${ }^{66}$

The most studied $B b$ adhesins are the decorin binding proteins (Dbp), DbpA and DbpB. Decorin is a small leucinerich proteoglycan (SLRP) that "decorates" collagen. ${ }^{67}$ Small leucine-rich proteoglycans are key regulators of matrix assembly and cellular growth, which helps account for why $B b$ seeks to be near them. Natural selection may favor $B b$ 's predilection for ECM tissue because it contains ample nutrition, pathway support, environmental cues, and less immune cell and antibody traffic than blood or lymph.

Barthold et $\mathrm{al}^{68}$ demonstrated in mice that antibodies against DbpA were able to resolve $B b$-mediated inflammation in joint and heart tissue, but surprisingly, without reducing the number of spirochetes found in homogenates of these tissues. ${ }^{68}$ Thus $B b$ may, when confronted with certain tissuespecific antibodies, seek cover in more defensive locations within that tissue region and in the process, inflammation resolves at least temporarily.

Barthold et $\mathrm{a}^{68}$ also reported that the adoptive transfer of lymphocytes and the passive transfer of serum and antisera to $\mathrm{DbpA}$ had no detectable effect on $B b$ gene transcription, yet immunochemistry studies revealed that spirochetes had moved from heart base tissue and synovium to vessel walls, tendons, and ligaments after the transfers. This is consistent with $B b$ 's chemoattraction for collagenous tissue, and with the findings of Zambrano et $\mathrm{al}^{69}$ that $B b$ binds to, invades, and colonizes native type 1 collagen lattices even in the absence of decorin.

Shi et $\mathrm{al}^{70}$ showed that DbpA and DbpB make similar contributions to infectivity, but dissimilar contributions 
to dissemination and tissue colonization. Wormser et $\mathrm{al}^{71}$ reported that $B b$ 's capacity for hematogenous dissemination to extravascular locations during early LD depends on genotype. These findings suggest that $B b$ strains possess a flexible set of chemotactic properties for use in avoiding host immune defenses.

Brisson et al ${ }^{72}$ subsequently examined $B b$ genotypes and found that certain OspC subtypes are more likely to disseminate to particular tissues than others. They showed biodiversity in the OspC allele that was greater among strains found within ticks than within the skin of EM lesions, and that OspC biodiversity in EM lesions was greater than that found in blood, synovial tissue, and CSF. Dissemination capacity, as determined by OspC variations, may interact with chemoreceptor variations to influence $B b$ predilections for different tissues within animal hosts.

The ECM helps $B b$ maintain infection by serving as a protective niche, a microhabitat where organisms can evade host immune defenses. Despite strong innate and adaptive immune responses against $B b$ antigens, immunocompetent animals infected with $B b$ can fail to sterilize the infection. Barthold et $\mathrm{al}^{73}$ found abundant amounts of $B b$ in the tendons and ligaments of mice despite strong humoral responses to $B b$ antigens. In a 2005 review, Cabello et al ${ }^{74}$ summarized the role that ECM tissue plays in $B b$ 's ability to persist by evading host immune systems and tolerating antibiotics. They raised questions for future research, including:

- Why does the strong host immune response not sterilize tissues of mice infected with $B b$ ?

- What are the interactions of $B b$ in the ECM with antibodies, complement, immune cells, and antibiotics?

- To what extent is $B b$ in the ECM metabolically active?

- Is the ECM a source of reinfection of other host tissues by $B b$ ?

While much is yet to be learned about how $B b$ chemotaxis, adhesion, and niche-seeking varies in response to changes within the terrain of the host, published data show a clear tendency for $B b$ to seek target molecules in the ECM, where host immune pressures are less intense, making persistent infectivity possible, if not probable.

\section{Quorum sensing and biofilm-like behavior} Indiscriminate use of antibiotics leads to the development of antibiotic-resistant microbial pathogens. This growing problem in the management of infectious disease stems from a widespread failure to understand the different natures of acute versus chronic infections. In many acute infections, the microbes responsible involve a single species that disseminates in a planktonic, free-floating fashion. In chronic infections, infectious microbes are found in biofilms - complex polymicrobial communities embedded within an exopolymeric gel.

The late J William Costerton (1934-2012) is widely perceived as the father of biofilm science. He was a prolific researcher and reviewer of advances in the scientific understanding of biofilms and their associations with chronic disease. ${ }^{75-78}$ Costerton et $\mathrm{al}^{79}$ established that biofilms were a common yet widely unrecognized cause of persistent infection. They warned physicians that biofilm science was raising legitimate concerns about how thoroughly we understand the infections we treat. The authors felt that our planktonic paradigm for antibiotic use applied extremely well to acute, highly virulent infections, but that they may fail when applied to chronic, polyphasic biofilm-associated infections. ${ }^{80}$

Quorum sensing refers to the ability of taxonomically diverse microbes to detect cell density thresholds and release diffusible signals that in turn, induce changes in gene expression involving other species in the vicinity. ${ }^{81}$ Quorum quenching refers to the process by which microbes inhibit quorum sensing. Research energy is focusing on what can be learned about microbial quorum sensing inhibitors and then translated into novel forms of antibiotic able to inhibit the formation of, and the ongoing signaling within, biofilmbased polymicrobial communities. ${ }^{82}$

When cell density conditions for a quorum are sensed, a participating microbe will trigger the production of an autoinducer molecule. The primary mechanism for this involves a series of enzymatic reactions that culminates in the use of the LuxS enzyme in the synthesis of a class of pheromones known as autoinductor (AI)-2. ${ }^{83}$ Among the three autoinduction molecules so far identified (AI-1, AI-2, and AI-3), AI-2 is present in both gram-negative and grampositive bacteria, and is therefore considered the "universal" autoinduction signal, although varied mechanisms for bacterial production of AI-2 are suspected. ${ }^{84}$

Stevenson and $\mathrm{Babb}^{85}$ have shown that $B b$ encodes a functional LuxS enzyme that would enable $B b$ to synthesize AI-2 and therefore participate in the potential benefits of quorum sensing. Babb et $\mathrm{al}^{86}$ subsequently characterized the molecular mechanism involved. Although our scientific understanding of $B b$ 's capacity to participate in quorum sensing remains fragmentary, Parveen and Cornell ${ }^{87}$ have demonstrated the importance of methylthioadenosine/ S-adenosylhomocysteine (MTA/SAH) nucleosidase and its ability to drive the formation of autoinducers, noting 
that MTA/SAH nucleoside inhibitors are highly effective at blocking autoinduction by $B b$. MTA/SAH nucleosidase inhibitors are therefore also of interest for their potential to disrupt biofilm formation.

Specific interspecies cross-talk patterns within biofilm have coevolved. Bacteria in biofilms persist in animal hosts by a strategy that might be characterized as tenacious survival as opposed to aggressive virulence, and the infections can linger for months, years, or even a lifetime. ${ }^{88}$ Peleg at al ${ }^{89}$ described medically important interactions between taxonomically diverse microorganisms, including the exchange of diffusible signal factors between Klebsiella pneumoniae and Candida albicans. Pseudomonas aeruginosa releases a signal that prevents the yeast form of $C$. albicans from morphing into its hyphal form..$^{90}$ The yeast form of $C$. albicans releases a signal that inhibits local macrophage activity, which may allow inocula of $P$. aeruginosa to become more virulent. ${ }^{91}$

The familiar mechanisms of antibiotic resistance, such as efflux pumps, modifying enzymes, and target mutations, ${ }^{92}$ do not seem to apply to bacterial protection within biofilm. Even highly sensitive bacteria with no genetic basis for resistance can, when embedded within biofilm, survive minimum inhibitory concentrations of antibiotics that are effective at stopping the growth of planktonic forms of the same bacteria. ${ }^{93}$ These findings support the conjecture that the current antibiotic treatment standard for LD may prove ineffective in cases where antibiotic-tolerant colonies of $B b$ may already be established in a host prior to initial antibiotic treatment.

Quorum sensing induces biodiverse microbes to work together to gain advantages against their host. While local cooperation among biofilm-based bacteria routinely occurs, Nadell et $\mathrm{al}^{94}$ point out that conflict among species within biofilms also occurs. They argue that signs of conflict among species within biofilms are to be expected because conflict provides a mechanism for maintaining balance within polymicrobial communities.

Stoodley et $\mathrm{al}^{95}$ have shown that mixed-species cell clusters can detach from biofilm and disseminate elsewhere within a system. They used a closed laboratory-based system to study how fluid flow dynamics affected the detachment of cell clusters from biofilm. This work has both clinical and public health implications, as it suggests that biofilms within living systems can be exposed to shear forces strong enough to cause detachment and dissemination elsewhere in the host body or ecosystem. As a mechanism for dispersal within animal hosts, this makes biofilm detachment and dissemination analogous to tumor cell metastasis.
Steere at $\mathrm{al}^{96}$ showed that arthritic signs and symptoms show up an average of 6 months after hematogenous dissemination and presumed seeding of joint tissues by $B b$. Nowakowski et $\mathrm{al}^{97}$ showed that blood cultures are negative in patients with Lyme arthritis. Synovial fluid samples from Lyme arthritis patients routinely show evidence of $B b$ DNA by polymerase chain reaction (PCR), yet they have shown an absence of viable spirochetes as determined by negative culture and the absence of messenger ribonucleic acid (mRNA) transcripts. ${ }^{98,99}$

Persing et $\mathrm{al}^{100}$ used PCR methods to show a disparity between $B b$ chromosomal and plasmid DNA in synovial fluid samples. They determined that plasmid DNA, but not chromosomal DNA, was present inside blebs (membranebound vesicles) that were being shed into the joint space. They raised the question as to whether metabolically active spirochetes could be releasing DNA into their surroundings.

Wormser et $\mathrm{al}^{101}$ published an interesting hypothesis that might account for these findings. They obtained synovial fluid from the knee of a patient with Lyme arthritis prior to antibiotic treatment. They saw intact spirochetes on microscopic examination, which led them to believe that they had for the first time at their center cultivated $B b$ from synovial fluid. It turned out that the spirochetes were nonmotile and enmeshed in a chemically undefined matrix. They concluded that the spirochetes in this patient's synovial fluid were dead but morphologically preserved "in a manner somewhat analogous to organisms in amber."101 They postulated that upon dissemination to joint tissue, $B b$ becomes enmeshed in a host-derived matrix of fibrous and collagenous tissue, and that some of this material could eventually detach and make its way into the joint space. Once in the joint space, they theorized, spirochete antigens might stimulate an inflammatory response. The amber theory implies that Lyme arthritis is a sterile, postinfectious process triggered by immunogenic spirochete parts enmeshed in a chemically undefined collagenous matrix.

In light of the progress in biofilm science detailed above, it is also possible to hypothesize that the intact spirochetes seen enmeshed in a matrix were not dead but viable, yet noncultivable due to metabolic activity too low for Barbour-Stoenner-Kelly (BSK) medium to foster growth and division. It is also conceivable that the matrix material was biofilm of microbial origin, perhaps mixed with host matrix elements, clusters of which detached by shear forces on joint tissue and found their way into the synovial fluid. Analysis of synovial fluid and tissue from Lyme arthritis 
patients might help determine if both the amber hypothesis (nonviable enmeshed spirochetes) and the biofilm hypothesis (viable enmeshed spirochetes) have the power to explain the clinical evolution of Lyme arthritis. It is worth noting here that not all biofilms have the same composition, and that animal ECM tissue may serve as a suitable biofilm substitute, or a preferred location for biofilm formation.

Sapi et al ${ }^{102}$ analyzed in vitro aggregates of $B b$ and found signs of biofilm formation. Atomic force microscopy (AFM) showed that multilevel rearrangements took place at different stages of aggregate development, producing a complex that continuously reorganized the structure. Chemical analysis of the extracellular substrate found sulfated and nonsulfated forms of polysaccharide, including alginate, which forms a viscous gum able to provide $B b$ with a source of nutrition and hydration. Calcium was present and when mixed with alginate developed into a dense outer shell. They also detected extracellular DNA in the aggregates, which is required for bacterial biofilm formation, as shown by Whitchurch et al. ${ }^{103}$ Sapi et al ${ }^{102}$ conclude that based on their in vitro demonstration, $B b$ likely forms biofilm in vivo and that $B b$ likely uses biofilm as a refuge from diverse environmental stresses within animal hosts.

\section{Horizontal gene transfer}

Bacteria can transmit genes vertically to daughter cells, or by HGT. Three forms of HGT have been classified: transformation, conjugation, and transduction. Transformation occurs when exogenous DNA is taken up through cell membranes, incorporated into a host genome, and expressed in the new host. Conjugation occurs when DNA is transferred between host and recipient bacterial cells in direct contact. Transduction refers to phage-mediated transfer of bacterial DNA from one host to another.

The capacity to acquire and incorporate foreign DNA by means of HGT can help bacteria develop improved mechanisms for infectivity, virulence, and antibiotic resistance. Molin and Tolker-Nielsen ${ }^{104}$ showed that gene transfer by plasmid conjugation and DNA transformation happens efficiently in biofilms, and that this process helps stabilize the biofilm structure. Ma and Bryers ${ }^{105}$ used confocal scanning microscopy and noninvasive image analysis to show that biofilm bacteria appear to "sense" the presence of antibiotics to which they are resistant, which causes them to enhance the spread of their resistance genes through plasmid conjugation.

Humphrey et al ${ }^{106}$ documented the first evidence of genetic transduction in a spirochete. They determined that the virus of Serpulina hyodysenteriae (VSH)-1 bacteriophage found in the spirochete Serpulina hyodysenteriae was able to transduce antibiotic-resistance markers efficiently between different strains. Eggers et $\mathrm{l}^{107}$ identified a $B b$ bacteriophage, $ø \mathrm{BB}-1$, and showed that it could resist nuclease action and was therefore not to be confused with membrane-bound vesicles containing DNA.

Alitalo et $\mathrm{al}^{40}$ found that $B b$ plasmids harboring OspE paralogs share homology with bacteriophages and that plasmids mediate the horizontal transfer of the genetic material that encodes for the $B b$ 's resistance to the host alternative complement pathway. Alitalo et al ${ }^{108}$ also found that while many strains of Borrelia garinii ( $B g$ ) carry plasmid-derived OspE genes, most do not express factor $\mathrm{H}$-binding proteins, yet certain neuroinvasive strains of $\mathrm{Bg}$ can express factor $\mathrm{H}$-binding proteins. Solheim et $\mathrm{al}^{109}$ found that biofilm creates a friendly environment for dissemination of plasmid-derived shiga-toxin genes, showing enhancement of virulence by means of transduction.

Madsen et $\mathrm{al}^{110}$ describe interactions between biofilm formation and HGT that make it clear what a desirable lifestyle they can create for bacterial communities. Biofilms host vast numbers of densely packed microbes within sessile communities, making them ideal locations for HGT by transformation, plasmid conjugation, and phage transduction. Biofilm communities appear to be incubators for microbial innovation by means of HGT. They create continual de novo mechanisms for adaptations to host immune responses, and in all likelihood, to would-be antibiotic regimens and vaccines as well. ${ }^{11}$

From the standpoint of evolutionary and ecological theory, it is little wonder that the biofilm life cycle leads to the production of differentiated, highly motile forms known as dispersal cells. McDougald et $\mathrm{al}^{112}$ review the life cycle of biofilm and the mechanisms regulating dispersal. Describing analogies between the life histories of biofilm and of eukaryotes, they show that both entail the alternation of sessile and mobile dispersal phases, the generation of variation prior to dispersal, and the programmed production of phase transitions. Eukaryotes appeared on earth somewhere between 1.6 and 2.1 billion years ago. ${ }^{113}$ Prokaryotes like $B b$ may use biofilm to attain the capacity for dispersal within their hosts, improving the chances of eventual transmission from host to vector.

The cooperation between biofilm, HGT, and bacterial dispersal mirrors one of the major transitions in social evolution, during which the selective advantages of intraspecies genetic variation came to include the selective 
advantages of interspecies mutualisms - advantages that play out in microecological niches ranging from alpine streams and coral beds to the matrix-like tissues of animal hosts. In LD, we may be witnessing the evolution of a new form of chronic infection - one that survives within true biofilm or within the biofilm-like matrix tissue of the animal host. Such colonies would be sufficiently protected from host immunity to engage in ongoing gene transfer experiments. Perhaps such experiments resulted in the evolution of adaptive nonspirochetal $B b$ morphologies.

\section{Atypical forms}

Some 100 years ago European researchers suspected that spirochetes could assume more forms than the classical spiral form for which they were known. ${ }^{14-116}$ More recently, electron microscopy has revealed detailed images of spherical and colonial morphologies for Treponema species. ${ }^{117,118}$ In the past several years, advanced imaging methods have been applied to the study of spirochetes. Investigations of $B b$ morphologies reveal conclusive evidence for nonspirochetal forms that change in response to environmental conditions.

Using dark field AFM and immunohistochemical methods, Miklossy et al ${ }^{119}$ observed atypical cystic, rolled, looped, ring-shaped, globular, spherical, and granular forms in two strains of $B b$ (B31 and ADB1). AFM images showed rolled spirochetes within cystic structures, and rolled spirochetes enveloped by thickened external membranes similar to those observed by dark field microscopy. These membranes bound to the anti-OspA antibody. The atypical forms were induced when exposed to unfavorable conditions including osmotic shock, heat shock, and binding agents.

These findings confirm the $B b$ pleomorphism previously shown by Mursic et al. ${ }^{120}$ Brorson and Brorson ${ }^{121}$ showed that motile $B b$ spirochetes inoculated into CSF converted into cystic forms within 1 to 24 hours. In this study, when the cystic forms were transferred into a rich BSK medium, they reverted back into mobile spirochetes within 9 to 17 days of incubation.

The same team also showed that when placed into a BSK culture medium without rabbit serum, motile $B b$ would convert into cystic forms, and when transferred to a BSK culture medium with rabbit serum, motile spirochetes would reemerge from the cystic forms. ${ }^{122}$ The medium without the rich additive of rabbit serum did not significantly change after inoculation with spirochetes, suggesting that the transition from a spirochetal form into a cystic form required little metabolic activity. Transmission electron microscopy images from this study include a series of cross-sectional views of spirochetes within cystic envelopes engaged in behaviors that remain poorly understood. Whatever they are doing within these cyst-like structures they do it without expending much energy.

Miklossy et al ${ }^{123}$ studied $B b$ 's pleomorphic changes both in friendly BSK 2 media and following $B b$ infection of cultures of chicken and rat neurons, as well as rat and human astrocytes. Atypical forms were seen within 1 hour of exposure to environmental stress. In these induced infections, large colony-like aggregates formed that were anti- $B b$ positive. Extracellular and intracellular ring-shaped and spherical forms stained positive for OspA antibody. Blebs were seen emerging from coiled as well as rolled spirochete forms. When atypical forms were transferred from stressed neuronal cultures to the friendly BSK 2 medium, typical spiral forms of $B b$ were eventually recovered.

The authors found similar findings in vivo. $B b$ cultured from the CSF of three patients with Lyme neuroborreliosis produced atypical forms following environmental stress. Post mortem analyses of the brains of these patients found immunohistochemical evidence for OspA immunoreactivity. They found ring-shaped, rolled, and cystic forms of $B b$ in frontal cortex sections from each of the three brain specimens. Control postmortem brain sections were negative for microscopic or immunohistochemical evidence of infection with $B b$. In one neuroborreliosis patient whose $\mathrm{CSF}$ culture had yielded the ADB1strain of $B b$, postmortem immunostaining of microglia and astrocytes revealed reactivity consistent with active inflammation, implicating $B b$ as the cause.

Livengood and Gilmore ${ }^{124}$ documented the ability of $B b$ to invade human neuronal and glial cells. Miklossy et al ${ }^{123}$ reported that $B b$ induces beta-amyloid deposition and other changes seen in Alzheimer's disease. In Miklossy's earlier work, ${ }^{119}$ the outer membrane of the cystic form reacts to the anti-OspA antibody, suggesting that cystic forms are either more immune resistant than motile spirochetes, or that they effectively evade the immune system by finding intracellular or immune-privileged tissue locations.

Sapi et $\mathrm{a}^{125}$ explored the effects of doxycycline, amoxicillin, tigecycline, metronidazole, and tinidazole on various $B b$ morphologies. They found that doxycycline reduced spirochetal forms by $90 \%$ but doubled the number of round body forms. As a group, the five antibiotics reduced the formation of biofilm-like colonies by only $30 \%$ to $55 \%$. Tinidazole reduced the number of viable forms by $90 \%$. The other antibiotics reduced viable forms by only $15 \%$ to $30 \%$. This study reveals strikingly different effects for different 
antibiotics and antibiotic combinations applied to spirochetal and atypical forms of $B b$. The authors conclude that persistence of viable $B b$ following antibiotic treatment likely represents failure to sterilize a recalcitrant chronic infection suffered by some patients with LD. This accounts for how $B b$ might be able to persist despite antibiotic challenges deemed adequate by published standards. Though cystic or cell wall-deficient forms of $B b$ have yet to be documented in vivo (let alone proven to be infectious), the work of Sapi et al ${ }^{125}$ raises the question as to whether $B b$ can induce the persister cells documented in other bacterial species.

\section{Persister cells}

In 1944, Bigger ${ }^{126}$ discovered bacteria that were able to survive penicillin and called them "persisters." For every million bacteria in a colony, Bigger" ${ }^{126}$ found roughly one persister. The relative rarity of these cell types made research on bacterial persistence difficult. In the 1980s, Moyed and Bertrand ${ }^{127}$ discovered Escherichia coli mutants that produced much higher rates of persisters, which made bacterial persistence research more feasible. The data show that as much as $1 \%$ of growing bacterial populations are comprised of persisters.

While no published research to date documents a persister capability for $B b$, discussion in this section is relevant to speculation about whether $B b$ might possess this important trait, an issue relevant to determining the ability of $B b$ to persist in a transmissible form following antibiotic challenge.

The selection advantages of bacterial persistence, and the resulting ability of this mechanism to help microbes survive antibiotic challenge, are altering the paradigm physicians use to understand chronic infection. Jayaraman ${ }^{128}$ notes that bacterial persistence is attracting the attention of researchers in fields ranging from microbiology and infectious disease to evolutionary and social biology.

Persister bacteria are dormant phenotypic variants that do not resist antibiotics by means of gene mutation, but instead tolerate antibiotics because most antibiotics need actively growing or dividing microbial cells in order to be effective. Resistance mechanisms prevent antibiotics from hitting a target, whereas tolerance mechanisms make the targets invisible, creating small subpopulations of microbes able to withstand antibiotic attack by going dormant.

Lewis $^{129}$ reviewed the mechanisms of persister formation. Global regulator genes manage the process by which antibiotic-susceptible bacteria become dormant bacteria tolerant to antibiotics. This process entails independent parallel mechanisms for dialing down metabolic activity. A common mechanism makes use of plasmid-derived toxinantitoxin modules. HipA, the first gene linked to persister formation, is a toxin from a kinase family that phosphorylates an elongation factor - an action that blocks RNA translation and leads to dormancy. ${ }^{130}$ Hansen et al ${ }^{131}$ recently identified the pathways responsible for HipA-mediated persistence, revealing new targets for disrupting HipA's role in antibiotic tolerance.

Persisters would be especially problematic when located within biofilm or in immune-privileged niche tissues within the host. Spoering and Lewis ${ }^{132}$ noted that biofilm-based bacteria and planktonic bacteria are equally capable of producing persister cells that are able to tolerate antibiotics. Persisters in biofilm or biofilm-like niches would have the added advantage of residing in locations that are less visible to host immune defenses.

In their review on bacterial quorum sensing, quorum signaling, and biofilms, Jayaraman and Wood ${ }^{133}$ describe the circuits involved in communication within species, between species, and between kingdoms. They note that antibiotic tolerance is not a heritable trait, but disrupting quorum signaling circuits offers a way to block biofilm formation and thus prevent the induction of persisters.

\section{Persistent infectivity postantibiotic challenge}

To date, no evidence exists concerning whether $B b$ has the capacity to tolerate antibiotics by virtue of the bacterial persistence pathways described above, yet convincing animal studies demonstrate that viable $B b$ persist in tissues despite adequate antibiotic challenge. ${ }^{134-138}$

In a landmark study, Barthold et a ${ }^{134}$ used tigecycline to treat mice infected with $B b$ and compared the results to salineonly treatment (negative effect controls) and ceftriaxone treatment (positive effect controls). The treatment groups included the early dissemination phase (1 week), the early immune response phase ( 3 weeks), and the late dissemination phase (12 weeks). Tissue transplantation from culturenegative, treated mice into uninfected SCID mice resulted in dissemination of $B b$ DNA in the recipient mice. In addition, sterile ticks became infected with $B b$ after taking blood meals from the recipient mice. This showed that noncultivable yet viable $B b$ can persist in antibiotic-treated mice and be transmitted to sterile tick vectors. It raises the possibility that circulating signals triggered by a feeding tick can rouse $B b$ from a noncultivable form to a mobile, signal-tracking form that can move into a fresh vector and perhaps a friendlier 
new animal host. A more definitive step for research on this question would be to show that such newly infected tick vectors can transmit those spirochetes to sterile animal hosts, and that those spirochetes can disseminate within those hosts. And if they prove again to be noncultivable, they should at least yield the characteristic markers of inflammation and antigen-specific host immune responses know to be produced by infective spirochetes.

In the first of three studies, Yrjänäinen et $\mathrm{al}^{135}$ showed that after antibiotic eradication of $B g$ spirochetes in mice, persistent arthritis occurs. In a second study, they found that after apparent eradication of spirochetes with ceftriaxone, treatment with immune-suppressing antitumor necrosis factor-alpha $(\mathrm{TNF}-\propto)$ activated viable, previously noncultivable $B b$ spirochetes within 4 weeks. ${ }^{136}$ In a third study, Yrjänäinen et al $^{137}$ again treated $B b$-infected mice with ceftriaxone. All postmortem samples were culture-negative, yet they detected $B b$ DNA in the joints of $30 \%-100 \%$ of the treated mice. The authors concluded that joints, or the tissue adjacent to joints, serve as a niche for viable $B b$ in ceftriaxone-treated mice. ${ }^{137}$

Embers et $\mathrm{al}^{138}$ produced a definitive demonstration of postantibiotic treatment persistence of $B b$ in nonhuman primates. Their team performed two experiments to assess posttreatment persistence by $B b$ in rhesus macaques. They inoculated the animals with laboratory strains of $B b$ (JD1 and B31 isolate 5A19). In the first study, inoculation resulted in positive skin cultures for $B b$, antibodies to wholecell $B b$ antigen by enzyme-linked immunosorbent assay (ELISA), and positive C6 ELISA for $B b$ in all animals. In the second study, infection was confirmed by serology and PCR detection of $B b$ in skin biopsies. Antibiotic treatment was administered at two different phases of disseminated infection: early and late.

In experiment 1 (late dissemination phase), 24 animals were inoculated with the JD1 strain of $B b$ by means of intraperitoneal, subcutaneous, and intradermal injection. At 27 weeks postinoculation, 12 animals were treated with intravenous ceftriaxone $(25 \mathrm{mg} / \mathrm{kg}$ ) for 30 days, followed by 60 days of oral doxycycline $(2 \mathrm{mg} / \mathrm{kg}$ ) twice daily. This regimen recapitulates the regimen used by Klempner et al ${ }^{139}$ in their National Institutes of Health (NIH)-sponsored human clinical trials published in 2001. The mean doxycycline concentration in the treated animals reached 6.7-fold the minimum inhibitory concentration of $0.31 \mathrm{mg} / \mathrm{L}$.

The animals were kept for 6 months following treatment termination, at which point tissue samples were collected for in vitro culture of $B b$ from skin and other organ specimens.
The researchers also performed quantitative real-time PCR for the detection of $B b$ OspA and flaB DNA targets, and for reverse transcriptase PCR and total RNA from heart and brain specimens. In addition, they examined gross pathology and histopathology. Immunofluorescence microscopy found evidence for both spirochetes and inflammation in various heart and brain tissue samples.

Only one of the treated animals was culture positive for $B b$. In untreated animals, PCR for DNA targets detected spirochetes in dorsal root ganglia in one animal, and heart in another. In one of the treated animals, PCR was positive in the meninges, bladder, spleen, and lungs. Surprisingly, for DNA targets, the difference between treated and untreated animals was not statistically significant.

Two of the untreated animals were positive for RNA transcripts - one in the heart, and one in the brain. Likewise, two of the treated animals were positive for RNA transcripts one in the heart, and one in both the heart and the brain. Again surprisingly, the difference between treated and untreated was not statistically significant.

No gross lesions were observed in any of the animals. On histopathology, three animals, all of them treated, showed moderate to severe inflammatory lesions in the heart. On immunofluorescence staining, intact spirochetes were not detected (they would have to lie perfectly parallel to the tissue section to be seen intact), but they did find numerous immunofluorescence-positive specimens of spirochetal fragments both in treated and untreated groups. Once again, the difference between groups was not statistically significant, suggesting that antibiotics administered to adhere to current standards possess a limited capacity to produce total eradication of $B b$ from animal hosts.

In experiment 2 (the early dissemination phase), 16 weeks postinoculation, five animals were treated with a 28-day regimen of oral doxycycline as indicated by IDSA guidelines for early-disseminated $B b$ infection. ${ }^{3}$ They were treated at a dose of $12 \mathrm{mg} / \mathrm{kg} /$ day to ensure an effective serum level. Then, at 7 or 11 months postinoculation, the researchers secured xenodiagnosis by showing that laboratory-reared, uninfected Ixodes scapularis nymphs became infected after taking a blood meal from macaques that had been treated with doses of doxycycline that IDSA guidelines considers adequate to eradicate all $B b$ spirochetes in an infected animal host. As with Barthold et al, ${ }^{134}$ a next step in documenting infectivity would be to show that such newly infected ticks transmit the spirochetes to sterile animal hosts and produce antigen-specific immune responses in those hosts. 
In experiment 2, the researchers also extracted RNA from animal tissues (to remove residual DNA), followed by amplification of transcripts for OspA and bbf26 (a gene found on linear plasmid 28-1, which also encodes the parent gene of the $\mathrm{C} 6$ diagnostic peptide). Using specified primers, they documented the presence of metabolically-active spirochetes despite an IDSA-adherent antibiotic challenge. The authors also confirmed that the identity of the metabolically-active strains of $B b$ found in the tissues of treated animals matched strains used during inoculation.

Serial measures of anti-C6 antibody (ELISA) in treated and untreated animals showed expected decreases in the C6 antibody in treated animals, and two patterns in untreated animals: either sustained elevations or declines that were more gradual than those seen in antibiotic-treated animals.

Taken together, culture, PCR, mRNA transcript, and immunohistochemical studies suggest that while C6 ELISA can be a useful marker for antibiotic-mediated decreases in immunogenic $B b$ spirochetes, viable, metabolically active, infective $B b$ spirochetes nonetheless persist in tissues despite standard antibiotic treatment and despite the return of C6 ELISA levels to preinfectious baselines. In other words, elevated C6 ELISA levels are a trustworthy indicator of the presence of viable Lyme spirochetes, but low C6 ELISA levels are not trustworthy indicators of Lyme spirochete eradication.

Embers et $\mathrm{al}^{138}$ addressed several of the key issues identified by Wormser and Schwartz ${ }^{10}$ in their 2009 review that focused on studies by Bockenstedt et al, ${ }^{141}$ Hodzic et al, ${ }^{142}$ and Straubinger et al, ${ }^{143}$ all of which documented the persistence of $B b$ in the tissues of animals despite the antibiotic challenge.

Evidence from the studies by Barthold et al, ${ }^{134}$ Yrjänäinen et al, ${ }^{135-137}$ and by Embers et al ${ }^{138}$ raise critical questions about the reliability and generalizability of initial interpretations of the four NIH-sponsored randomized, controlled trials that evaluated antibiotic retreatment in patients with persistent symptoms following standard LD treatment. ${ }^{139,144,145}$ These studies reported statistically insignificant improvements in function as a result of retreatment, and findings were widely taken as proof that persistent LD is not caused by chronic infection.

Recent analyses cast doubt on these interpretations. Fallon et $\mathrm{al}^{146}$ reviewed published interpretations of the four NIHsponsored trials. Their review of the Study and treatment of post-Lyme disease (STOP-LD) trial by Krupp et a ${ }^{144}$ counters prior critiques of this trial and demonstrates that treatment with intravenous ceftriaxone had a statistically significant and clinically meaningful effect on fatigue - the primary outcome measure in this study. They also point out that the Post-Treatment Lyme Encephalopathy trial ${ }^{145}$ demonstrated statistically significant and clinically meaningful benefits on pain and physical function.

DeLong et al ${ }^{147}$ performed a biostatistical review of these four trials and concluded that the primary outcomes originally reported as statistically insignificant were likely underpowered. The authors concluded that ceftriaxone treatment produced clinically meaningful improvements in fatigue and cognitive functioning, and that persistent LD patients with worse baseline pain and physical functioning are likely to experience significant and sustained improvement from such treatment. The authors called for additional studies of persistent LD treatment using oral antibiotic regimens, and for eliminating postinfectious LD as a criterion for eligibility, since evidence is mounting that in many patients, the morbidity associated with so-called postinfectious LD can be caused by persistent $B b$ infection.

\section{Conclusions}

Well-established mechanisms for immune system evasion make a highly plausible case for $B b$ 's ability to establish an infection that could survive host immune defenses during early and late phases of dissemination. Video evidence reveals how quickly $B b$ can exit the vascular compartment and translocate into ECM tissues. Preliminary evidence suggests that $B b$ may participate in quorum sensing, biofilmlike behavior, and persister cell induction. Such mechanisms would help explain $B b$ 's ability to survive not just initial antibiotic therapy, but ongoing aggressive antibiotic therapy as well. Credible evidence supports the conclusion that LD can be a recalcitrant and chronic relapsing infection in animal hosts. While postinfectious immune pathology likely accounts for certain aspects of the morbidity seen in LD patients following standard antibiotic treatment, ${ }^{101,148-150}$ such mechanisms were not the subject of this review.

Barthold et al ${ }^{134}$ demonstrated that neither standard nor more aggressive antibiotic treatments are able to clear persisting $B b$ from mice, implying that $B b$ survives antibiotic treatment by shifting into nondividing or slowly dividing forms that retain viability, and possibly infectiousness. Yrjänäinen et a ${ }^{136}$ demonstrated recalcitrant $B b$ infection by inducing immune inhibition. Embers et al ${ }^{138}$ demonstrated that viable $B b$ persists in nonhuman primate tissues despite antibiotic therapy, which is currently viewed as adequate for achieving complete eradication. This evidence confronts physicians with a dilemma: we know that viable and infectious $B b$ can survive an aggressive antibiotic challenge, yet we lack the evidence needed to guide us on how best to 
treat a persistent infection of this kind. As a result, paralysis on the part of physicians will continue, and patients will suffer for a lack of physicians willing to design an empirical care plan for a persistent infection that is difficult to document and treat.

Research in microbiology, immunology, and genetics should further investigate how Borrelia spirochetes use mechanisms for immune evasion, biofilm-like niche-seeking behavior, and antibiotic tolerance to survive antibiotic therapies. Animal and clinical research should investigate what happens to LD morbidity when treated with regimens that target such mechanisms. Studies should systematically explore regimens that administer agents in ways designed to fit an emerging paradigm for polymicrobial, polyphasic, chronic infections associated with multiple mechanisms for immune evasion and persistence. Future research on antibiotic treatment for LD in animal hosts should assess the effectiveness of pulsed, variable combinations of antibiotics for their abilities to disrupt the protective niches and evasive methods favored by these flexibly adaptive spirochetes. For example, use of a cephalosporin against spirochetal forms in the vascular compartment might be combined with pulsed dosing of tinidazole to cover spirochetal and atypical forms in matrix compartments. Such a regimen may yield better long-term outcomes than ceftriaxone or doxycycline alone. Botanical antimicrobial agents should be explored for their abilities to disrupt the protective niches and evasive methods favored by these flexibly adaptive spirochetes. Such studies might speed the translation of basic and clinical research into reliably positive results for people with persistent LD.

Based on well-designed post-treatment animal studies and ongoing delineation of $B b$ 's mechanisms for host immune evasion and persistence, we can reasonably conclude that some, possibly many, chronic LD patients suffer from symptoms related to persistent infection with $B b$. As inevitably happens in the evolution of scientific ideas, new research proves that the reality is more complex than we thought, and the time has now come to move beyond the divisiveness of the past into a more reality-based paradigm for research, education, and patient care. The question is no longer whether LD can survive an antibiotic challenge in order to become a persistent infection. High quality studies show not only that it happens, but they also show how it happens, and why we should not feel surprised that it happens. Our task in the new era is to determine which patients suffer from persistent LD, and to keep pressing for evidence-based wisdom to guide the physicians called upon to treat them.

\section{Disclosure}

The author reports no conflicts of interest in this work.

\section{References}

1. Adelson ME, Rao RV, Tilton RC, et al. Prevalence of Borrelia burgdorferi, Bartonella spp., Babesia microti, and Anaplasma phagocytophila in Ixodes scapularis ticks collected in Northern New Jersey. J Clin Microbiol. 2004;42(6):2799-2801.

2. Tokarz R, Jain K, Bennett A, Briese T, Lipkin WI. Assessment of polymicrobial infections in ticks in New York state. Vector Borne Zoonotic Dis. 2010;10(3):217-221.

3. Wormser GP, Dattwyler RJ, Shapiro ED, et al. The clinical assessment, treatment, and prevention of Lyme disease, human granulocytic anaplasmosis, and babesiosis: clinical practice guidelines by the Infectious Disease Society of America. Clin Infectious Dis. 2006;43(9): 1089-1134

4. Cameron D, Gaito A, Harris N, et al; for ILADS Working Group. Evidence-based guidelines for the management of Lyme disease. Expert Rev Anti Infect Ther. 2004;2(Suppl 1):S1-S13.

5. Maloney EL. The need for clinical judgment in the diagnosis and treatment of Lyme disease. Journal of American Physicians and Surgeons. 2009;14(3):82-89.

6. Johnson L, Stricker R. The Infectious Diseases Society of America Lyme guidelines: a cautionary tale about the development of clinical practice guidelines. Philos Ethics Humanit Med. 2010;5:9.

7. Dattwyler RJ. A commentary on the treatment of early Lyme disease. Clin Infect Dis. 2010;50(4):521-522.

8. Halperin JJ. Prolonged Lyme disease treatment: enough is enough. Neurology. 2008;70(13):986-987.

9. Auwaerter PG. Point: antibiotic therapy is not the answer for patients with persisting symptoms attributable to Lyme disease. Clin Infect Dis. 2007;45(2):143-148.

10. Stricker RB. Counterpoint: long-term antibiotic therapy improves persistent symptoms associated with lyme disease. Clin Infect Dis. 2007;45(2):149-157.

11. Cameron DJ. Proof that chronic lyme disease exists. Interdiscip Perspect Infect Dis. 2010;2010:876450.

12. Stricker RB, Lautin A, Burrascano JJ. Lyme disease: point/counterpoint. Expert Rev Anti Infect Ther. 2005;3(2):155-165.

13. Steere AC, Malawista SE, Snydman DR, et al. Lyme arthritis: an epidemic of oligoarticular arthritis in children and adults in three Connecticut communities. Arthritis Rheum. 1977;20(1):7-17.

14. Burgdorfer W, Barbour AG, Hayes SF, Benach JL, Grunwaldt E, Davis JP. Lyme disease-a tick-borne spirochetosis? Science. 1982; 216(4552):1317-1319.

15. Steere AC, Grodzicki RL, Kornblatt AN, et al. The spirochetal etiology of Lyme disease. N Engl J Med. 1983;308(13):733-740.

16. Asbrink E, Hovmark A. Early and late cutaneous manifestations of Ixodes-borne borreliosis (erythema migrans borreliosis, Lyme borreliosis). Ann N Y Acad Sci. 1988;539:4-15.

17. Steere AC. Lyme disease. N Engl J Med. 1989;321(9):586-596.

18. Fraser CM, Casjens S, Huang WM, et al. Genomic sequence of a Lyme disease spirochete, Borrelia burgdorferi. Nature. 1997; 390(6660):580-586.

19. de Silva AM, Fikrig E. Arthropod- and host-specific gene expression by Borrelia burgdorferi. J Clin Invest. 1997;99(3):377-379.

20. Schwan TG, Piesman J, Golde WT, Dolan MC, Rosa PA. Induction of an outer surface protein on Borrelia burgdorferi during tick feeding. Proc Natl Acad Sci U S A. 1995;92(7):2909-2013.

21. de Silva AM, Telford SR 3rd, Brunet LR, Barthold SW, Fikrig E. BorreliaburgdorferiOspA is an arthropod-specific transmission-blockingLyme disease vaccine. J Exp Med. 1996;183(1):271-275.

22. Weintraub P. Cure Unknown: Inside the Lyme Epidemic. New York, NY: St Martin's Press; 2008.

23. Ramamoorthi N, Narasimhan S, Pal U, et al. The Lyme disease agent exploits a tick protein to infect the mammalian host. Nature. 2005; 436(7050):573-577. 
24. Anguita J, Ramamoorthi N, Hovius JW, et al. Salp15, an ixodes scapularis salivary protein, inhibits $\mathrm{CD} 4(+) \mathrm{T}$ cell activation. Immunity. 2002;16(6):849-859.

25. Juncadella IJ, Garg R, Ananthnarayanan SK, Yengo CM, Anguita J. T-cell signaling pathways inhibited by the tick saliva immunosuppressor, Salp15. FEMS Immunol Med Microbiol. 2007;49(3):433-438.

26. Kubes M, Kocáková P, Slovák M, Sláviková M, Fuchsberger N, Nuttal PA. Heterogeneity in the effect of different ixodid tick species on human natural killer cell activity. Parasite Immunol. 2002;24(1):23-28.

27. Hovius JW, de Jong MA, den Dunnen J, et al. Salp15 binding to DC-SIGN inhibits cytokine expression by impairing both nucleosome remodeling and mRNA stabilization. PLoS Pathog. 2008;4(2):e31.

28. Gwakisa P, Yoshihara K, Long To T, Gotoh H, Amano F, Momotani E. Salivary gland extract of Rhipicephalus appendiculatus ticks inhibits in vitro transcription and secretion of cytokines and production of nitric oxide by LPS-stimulated JA-4 cells. Vet Parasitol. 2001;99(1):53-61.

29. Montgomery RR, Lusitani D, De Boisfleury Chevance A, Malawista SE. Tick saliva reduces adherence and area of human neutrophils. Infect Immun. 2004;72(5):2989-2994.

30. Hannier S, Liversidge J, Sternberg JM, Bowman AS. Characterization of the B-cell inhibitory protein factor in Ixodes ricinus tick saliva: a potential role in enhanced Borrelia burgdorferi transmission. Immunology. 2004;113(3):401-408.

31. Önder Ö, Humphrey PT, McOmber B, et al. OspC is potent plasminogen receptor on surface of Borrelia burgdorferi. J Biol Chem. 2012; 287(20):16860-16868.

32. Lagal V, Portnoï D, Faure G, Postic D, Baranton G. Borrelia burgdorferi sensu stricto invasiveness is correlated with OspC-plasminogen affinity. Microbes Infect. 2006;8(3):645-652.

33. Grab DJ, Perides G, Dumler JS, et al. Borrelia burgdorferi, hostderived proteases, and the blood-brain barrier. Infect Immun. 2005; 73(2):1014-1022.

34. Daha NA, Banda NK, Roos A, et al. Complement activation by (auto-) antibodies. Mol Immunol. 2011;48(14):1656-1665.

35. Ferreira VP, Pangburn MK, Cortés C. Complement control protein factor H: the good, the bad, and the inadequate. Mol Immunol. 2010; 47(13):2187-2197.

36. Thiel S, Gadjeva M. Humoral pattern recognition molecules: manninbinding lectin and ficolins. Adv Exp Med Biol. 2009;653:58-73.

37. Schuijt TJ, Hovius JW, van Burgel ND, Ramamoorthi N, Fikrig E, van Dam AP. The tick salivary protein Salp15 inhibits the killing of serum-sensitive Borrelia burgdorferi sensu lato isolates. Infect Immun. 2008;76(7):2888-2894.

38. Henningson AJ, Ernerudh J, Sandholm K, et al. Complement activation in Lyme neuroborreliosis - increased levels of C1q and $\mathrm{C} 3 \mathrm{a}$ in cerebrospinal fluid indicate complement activation in the CNS. J Neuroimmunol. 2007;183(1-2):200-207.

39. Alitalo A, Meri T, Rämö L, et al. Complement evasion by Borrelia burgdorferi: serum-resistant strains promote $\mathrm{C} 3 \mathrm{~b}$ inactivation. Infect Immun. 2001;69(6):3865-3891.

40. Alitalo A, Meri T, Lankinen H, et al. Complement inhibitor factor $\mathrm{H}$ binding to Lyme disease spirochetes is mediated by inducible expression of multiple plasmid-encoded outer surface protein E paralogs. J Immunol. 2002;169(7):3847-3853.

41. Hefty PS, Jolliff SE, Caimano MJ, Wikel SK, Akins DR. Changes in temporal and spatial patterns of outer surface lipoprotein expression generate population heterogeneity and antigenic diversity in the Lyme disease spirochete, Borrelia burgdorferi. Infect Immun. 2002;70(7):3468-3478.

42. Vink C, Rudenko G, Seifert HS. Microbial antigenic variation mediated by homologous DNA recombination. FEMS Microbiol Rev. 2011:1574-6976.

43. Zhang JR, Hardham JM, Barbour AG, Norris SJ. Antigenic variation in Lyme disease borreliae by promiscuous recombination of VMP-like sequence cassettes. Cell. 1997;89(2):275-285.

44. Kawabata H, Myouga F, Inagaki Y, Murai N, Watanabe H. Genetic and immunological analyses of VIs (VMP-like sequences) of Borrelia burgdorferi. Microb Pathog. 1998;24(3):155-166.
45. Norris SJ. Antigenic variation with a twist - the Borrelia story. Mol Microbiol. 2006;60(6):1319-1322.

46. Hastey CJ, Elsner RA, Barthold SW, Baumgarth N. Delays and diversions mark the development of $\mathrm{B}$ cell responses to Borrelia burgdorferi infection. J Immunol. 2012;188(11):5612-5622.

47. Dresser AR, Hardy PO, Chaconas G. Investigation of the genes involved in antigenic switching at the vlsE locus in Borrelia burgdorferi: an essential role for the ruvAB branch migrase. PLoS Pathog. 2009; 5(12):e1000680.

48. Lin T, Gao L, Edmonson DG, Jacobs MB, Philipp MT, Norris SJ. Central role of the Holliday junction helicase RuvAB in vIsE recombination and infectivity in Borrelia burgdorferi. PLoS Pathog. 2009; 5(12):e1000679.

49. Lawrenz MB, Wooten RM, Norris SJ. Effects of vIsE complementation on the infectivity of Borrelia burgdorferi lacking the linear plasmid Ip28-21. Infect Immun. 2004;72(11):6577-6585.

50. Bankhead T, Chaconas G. The role of VIsE antigenic variation in the Lyme disease spirochete: persistence through a mechanism that differs from other pathogens. Molec Microbiol. 2007;65(6):1547-1558.

51. Porcella SF, Schwan TG. Borrelia burgdorferi and Treponema pallidum: a comparison of functional genomics, environmental adaptations, and pathogenic mechanisms. J Clin Invest. 2001;107(6):651-656.

52. Norris SJ. How do lyme borrelia organisms cause disease? The quest for virulence determinants( ). Open Neurol J. 2012;6:119-123.

53. Liu J, Lin T, Botkin DJ, McCrum E, Winkler H, Norris SJ. Intact flagellar motor of Borrelia burgdorferi revealed by cryo-electron tomography: evidence for stator ring curvature and rotor/C-ring assembly flexion. J Bacteriol. 2009;191(16):5026-5036.

54. Sal MS, Li C, Motalab MA, Shibata S, Aizawa S, Charon NW. Borrelia burgdorferi uniquely regulates its motility genes and has an intricate flagellar hook-basal body structure. J Bacteriol. 2008; 190(6):1912-1921.

55. Charon NW, Goldstein SF, Marko M, et al. The flat ribbon configuration of the periplasmic flagella of Borrelia burgdorferi and its relationship to motility and morphology. J Bacteriol. 2009;191(2):600-607.

56. Kimsey RB, Spielman A. Motility of Lyme disease spirochetes in fluids as viscous as the extracellular matrix. J Infect Dis. 1990; 162(5):1205-1208

57. Charon NW, Cockburn A, Li C, et al. The unique paradigm of spirochete motility and chemotaxis. Ann Rev Microbiol. 2012;66:349-370.

58. Moriarty TJ, Norman UM, Colarusso P, Bankhead T, Kubes P, Chaconas G. Real-time high resolution 3D imaging of the lyme disease spirochete adhering to and escaping from the vasculature of a living host. PLoS Pathog. 2008;4(6):e1000090.

59. Xu H, Raddi G, Liu J, Charon NW, Li C. Chemoreceptors and flagellar motors are subterminally located in close proximity at the two cell poles in spirochetes. J Bacteriol. 2011;193(10):2652-2656.

60. Zhang K, Liu J, Tu Y, Xu H, Charon NW, Li C. Two CheW coupling proteins are essential in a chemosensory pathway of Borrelia burgdorferi. Mol Microbiol. 2012;85(4):782-794.

61. Sze CS, Zhang K, Kariu T, Pal U, Li C. Borrelai burgdorferi needs chemotaxis to establish infection in mammals and to accomplish its enzootic cycle. Infect Immun. 2012;80(7):2485-2492.

62. Parveen N, Leong JM. Identification of a candidate glycosaminoglycan-binding adhesin of the Lyme disease spirochete Borrelia burgdorferi. Mol Microbiol. 1998;35(5):1220-1234.

63. Guo BP, Brown EL, Dorward DW, Rosenberg LC, Höök M. Decorin-binding adhesins from Borrelia burgdorferi. Mol Microbiol. 1998;30(4):711-723.

64. Probert WS, Johnson BJ. Identification of a $47 \mathrm{kDa}$ fibrinonectinbinding protein expressed by Borrelia burgdorferi isolate B31. Mol Microbiol. 1998;30(5):1003-1015.

65. Iozzo RV. Matrix proteoglycans: from molecular design to cellular function. Annu Rev Biochem. 1998;67:609-652.

66. Iozzo RV. The family of small leucine-rich proteoglycans: key regulators of matrix assembly and cellular growth. Crit Rev Biochem Mol Microbiol. 1997;32(2):141-174. 
67. Wu RR, Couchman JR. cDNA cloning of the basement membrane chondroitin sulfate proteoglycan core protein, bamacan: a five domain structure including coiled-coil motifs. J Cell Biol. 1997; $136(2): 433-444$

68. Barthold SW, Hodzic E, Tunev S, Feng S. Antibody-mediated disease remission in the mouse model of lyme borreliosis. Infect Immun. 2006; 74(8):4817-4825.

69. Zambrano MC, Beklemisheva AV, Bryksin AV, Newman SA, Cabello FC. Borrelia burgdorferi binds to, invades, and colonizes native type I collagen lattices. Infect Immun. 2004;72(6):3138-3146.

70. Shi Y, Xu Q, Seemanaplli SV, McShan K, Liang FT. Common and unique contributions of decorin-binding proteins $\mathrm{A}$ and $\mathrm{B}$ to the overall virulence of Borrelia burgdorferi. PLoS One. 2008;3(10):e3340.

71. Wormser G, Brisson D, Liveris D, et al. Borrelia burgdorferi genotype predicts the capacity for hematogenous dissemination during early Lyme disease. J Infect Dis. 2008;198(9):1358-1364.

72. Brisson D, Baxamusa N, Schwartz I, Wormser GP. Biodiversity of Borrelia burgdorferi strains in tissues of Lyme disease patients. PLoS One. 2011;6(8):e22926.

73. Barthold SW, de Souza MS, Janotka JL, Smith AL, Persing DH Chronic Lyme borreliosis in the laboratory mouse. Am J Pathol. 1993; 143(3):959-971

74. Cabello FC, Godfrey HP, Newman SA. Hidden in plain sight: Borrelia burgdorferi and the extracellular matrix. Trend Microbiol. 2005; 15(8):350-354.

75. Costerton JW, Geesey GG, Cheng GK. How bacteria stick. Sci Am. 1978;238:86-95.

76. Donlan RM, Costerton JW. Biofilms: survival mechanisms of clinically relevant organisms. Clin Microbiol Rev. 2002;15(2):167-193.

77. Costerton JW, Cheng KJ, Geesey GG, et al. Bacterial biofilms in nature and disease. Ann Rev Microbiol. 1987;41:435-464.

78. Costerton JW, Lewandowski Z, Caldwell DE, Korber DR, LappinScott HM. Microbial biofilms. Ann Rev Microbiol. 1995;49:711-745.

79. Costerton JW, Stewart PS, Greenberg EP. Bacterial biofilms: a common cause of persistent infections. Science. 1999;284(5418):1318-1322.

80. Fux CA, Stoodley P, Hall-Stoodley L, Costerton JW. Bacterial biofilms: a diagnostic and therapeutic challenge. Expert Rev Anti Infect Ther. 2003;1(4):667-683.

81. Rutherford ST, Bassler BL. Bacterial quorum sensing: its role in virulence and possibilities for its control. Cold Spring Harb Perspect Med. 2012;2(11):Pii:a012427.

82. Kalia VC. Quorum sensing inhibitors. An overview. Biotechnol Adv. 2013;31(2):224-245

83. Surette MG, Miller MB, Bassler BL. Quorum sensing in Escherichia coli, Salmonella typhimurium, and Vibrio harveyi: a new family of genes responsible for autoinducer production. Proc Natl Acad Sci US A. 1999;96(4):1639-1644.

84. Sun J, Daniel R, Wagner-Döbler I, Zeng AP. Is autoinducer-2 a universal signal for interspecies communication: a comparative genomic and phylogenetic analysis of the synthesis and signal transduction pathways. BMC Evol Biol. 2004;4:36.

85. Stevenson B, Babb K. LuxS-mediated quorum sensing in Borrelia burgdorferi, the lyme disease spirochete. Infect Immun. 2002; 70(8):4099-4105.

86. Babb K, von Lackum K, Wattier RL, Wattier RL, Riley SP, Stevenson B. Synthesis of autoinducer 2 by the lyme disease spirochete, Borrelia burgdorferi. J Bacteriol. 2005;187(9):3079-3087.

87. Parveen N, Cornell KA. Methylthioadenosine/S-adenosylhomocysteine nucleosidase, a critical enzyme for bacterial metabolism. Mol Microbiol. 2011;79(1):7-20.

88. Stewart PS, Costerton JW. Antibiotic resistance of bacteria in biofilms. Lancet. 2001;358(9276):135-138.

89. Peleg AY, Hogan DA, Mylonakis E. Medically important bacterialfungal interactions. Nat Rev Micro. 2010;8(5):340-349.

90. Hogan D, Vik A, Kolter R. A Pseudomonas quorum-sensing molecule influences Candida albicans morphology. Mol Microbiol. 2004; 54(5):1212-1223.
91. Roux D, Gaudry S, Dreyfuss D, et al. Candida albicans impairs macrophage function and facilitates Pseudomonas aeruginosa pneumonia in rats. Crit Care Med. 2009;37(3):1062-1067.

92. Walsh C. Molecular mechanisms that confer antibacterial drug resistance. Nature. 2000;406(6797):775-781.

93. Anderl JN, Franklin MJ, Stewart PS. Role of antibiotic penetration limitation in Klebsiella pneumoniae biofilm resistance to ampicillin and ciprofloxacin. Antimicrob Agents Chemother. 2000;44(7):1818-1824.

94. Nadell CD, Xavier JB, Foster KR. The sociobiology of biofilms. FEMS Microbiol Rev. 2009;33(1):206-224.

95. Stoodley P,Wilson S, Hall-Stoodley L, Boyle JD, Lappin-ScottHM, Costerton JW. Growth and detachment of cell clusters from mature mixed-species biofilms. Appl Environ Microbiol. 2001;67(12):5608-5613.

96. Steere AC, Schoen RT, Taylor E. The clinical evolution of Lyme arthritis. Ann Intern Med. 1987;107(5):725-731.

97. Nowakowski J, McKenna D, Nadelman RB, et al. Blood cultures for patients with extracutaneous manifestations of Lyme disease in the United States. Clin Infect Dis. 2009;49(11):1733-1735.

98. Nocton JJ, Dressler F, Rutledge BJ, Rys PN, Persing DH, Steere AC Detection of Borrelia burgdorferi DNA by polymerase chain reaction in synovial fluid from patients with Lyme arthritis. $N$ Engl J Med. 1994;330(4):229-234.

99. Li X, McHugh GA, Damle N, SikandVK, Glickstein L, Steere AC. Burden and viability of Borrelia burgdorferi in skin or joints of patients with erythema migrans or lyme arthritis. Arthritis Rheum. 2011;63(8):2238-2247.

100. Persing DJ, Rutledge BJ, Rys PN, et al. Target imbalance: disparity of Borrelia burgdorferi genetic material in synovial fluid from Lyme arthritis patients. J Infect Dis. 1994;169(3):668-672.

101. Wormser GP, Nadelman RB, Schwartz I. The amber theory of Lyme arthritis: initial description and clinical implications. Clin Rheumatol. 2012;31(6):989-994.

102. Sapi E, Bastian S, Mpoy CM, et al. Characterization of biofilm formation by Borrelia burgdorferi in vitro. PLoS One. 2012;7(10):e48277.

103. Whitchurch CB, Tolker-Nielsen T, Ragas PC, Mattick JS. Extracellular DNA required for bacterial biofilm formation. Science. 2002; 295(5559):1487.

104. Molin S, Tolker-Nielsen T. Gene transfer occurs with enhanced efficiency in biofilms and induces enhanced stabilisation of the biofilm structure. Curr Opin Biotechnol. 2003;14(3):255-261.

105. Ma H, Bryers JD. Non-invasive determination of conjugative transfer of plasmids bearing antibiotic-resistance genes in biofilm-bound bacteria: effects of substrate loading and antibiotic selection. Appl Microbiol Biotechnol. 2013;97(1):317-328.

106. Humphrey SB, Stanton TB, Jenson NS, Zuerner RL. Purification and characterization of VSH-1, a generalized transducing bacteriophage of Surpulina hyodsenteriae. J Bacteriol. 1997;179(2):323-329.

107. Eggers CH, Casjens S, Hayes SF, et al. Bacteriophages of spirochetes. J Mol Microbiol Biotechnol. 2000;2(4):365-373.

108. Alitalo A, Meri T, Comstedt P, et al. Expression of complement factor $\mathrm{H}$ binding immunoevasion proteins in Borrelia garinii isolated from patients with neuroborreliosis. Eur J Immunol. 2005;35(10):3043-3053.

109. Solheim HT, Seske C, Urdahl AM, Wasteson Y, Nesse LL. Biofilm as an environment for dissemination of stx genes by transduction. Appl Environ Microbiol. 2013;79(3):896-900.

110. Madsen JS, Burmølle M, Hansen LH, Sørensen SJ. The interconnection between biofilm formation and horizontal gene transfer. FEMS Immunol Med Microbiol. 2012;65(2):183-195.

111. Skotarczak B. Adaptation factors of Borrelia for host and vector. Ann Agric Environ Med. 2009;16(1):1-8.

112. McDougald D, Rice SA, Barraud N, Steinberg PD, Kjelleberg S. Should we stay or should we go: mechanisms and ecological consequences for biofilm dispersal. Nat Rev Microbiol. 2012;10(1):39-50.

113. Knoll AH, Javaux EJ, HewittD, Cohen P. Eukaryotic organisms is Proterozoic oceans. Phil Trans R Soc Lond B Biol Sci. 2006; 361(1470):1023-1038.

114. Herxheimer K. Zur kenntnis der Spirochaeta pallida [Knowledge advances on pallidum spirochetes]. München Med Wochshr (journal out of print). 1905;53:310-312. 
115. Sézary JL. Des formes atypiques et dégénératives du tréponéme pâle [The atypical and degenerative forms of Treponema pallidum]. Bull Mem Soc Med Hop Paris. 1907;24:114. French.

116. Fantham HB. Spirochaetes and their granule phase. Br Med J. 1916; 1(2881):409-411.

117. Umemoto T, Namikawa I, Yoshii Z, Konishi H. An internal review of the spherical body of Treponema macrodentium as revealed by scanning electron microscopy. Microbiol Immunol. 1982;26(3):191-198.

118. Umemoto T, Namikawa I, Yamamoto M. Colonial morphology of treponemes observed by electron microscopy. Microbiol Immunol. 1984;28(1):11-22.

119. Miklossy J, Kasas S, Zurn AD, McCall S, Yu S, McGeer PL. Persisting atypical and cystic forms of Borrelia burgdorferi and local inflammation in Lyme borreliosis. J Neuroinflammation. 2008;5:40.

120. Mursic VP, Wanner G, Reinhardt S, Wilske B, Busch U, Marget W. Formation and cultivation of Borrelia burgdorferi spheroplast-L-form variants. Infection. 1996;24(3):218-226.

121. Brorson O, Brorson SH. In vitro conversion of Borrelia burgdorferi to cystic forms in spinal fluid, and transformation to mobile spirochetes by incubation in BSK-H medium. Infection. 1998;26(3):144-150.

122. Brorson $\mathrm{O}$, Brorson $\mathrm{SH}$. Transformation of cystic forms of Borrelia burgdorferi to normal, mobile spirochetes. Infection. 1997; 25(4):240-246.

123. Miklossy J, Kis A, Radenovic A, et al. Beta-amyloid deposition and Alzheimer's type changes induced by Borrelia spirochetes. Neurobiol Aging. 2006;27(2):228-236.

124. Livengood JA, Gilmore RD Jr. Invasion of human neuronal and glial cells by an infectious strain of Borrelia burgdorferi. Microbes Infect. 2006;8(14-15):2832-2840.

125. Sapi E, Kaur N, Anyanwu S, et al. Evaluation of in-vitro antibiotic susceptibility of different morphological forms of Borrelia burgdorferi. Infect Drug Resist. 2011;4:97-113.

126. Bigger J. Treatment of staphylococcal infections with penicillin by intermittent sterilisation. Lancet. 1944;244(6320):497-500.

127. Moyed HS, Bertrand KP. HipA, a newly recognized gene of Escherichia coli K-12 that affects frequency of persistence after inhibition of murein synthesis. J Bacteriol. 1983;155(2):768-775.

128. Jayaraman R. Bacterial persistence: some new insights into an old phenomenon. J Biosci. 2008;33(5):795-805

129. Lewis K. Persister cells. Annu Rev Microbiol. 2010;64:357-372.

130. Schumacher MA, Piro KM, Xu W, Hansen S, Lewis K, Brennan RG. Molecular mechanisms of HipA-mediated multidrug tolerance and its neutralization by HipB. Science. 2009;323(5912):396-401.

131. Hansen S, Vulić M, Min J, et al. Regulation of the Escherichia coli HipBA toxin-antitoxin system by proteolysis. PLoS One. 2012; 7(6):e39185.

132. Spoering AL, Lewis K. Biofilms and planktonic cells of Pseudomonas aeruginosa have similar resistance to killing by antimicrobials. J Bacteriol. 2001;183(23):6746-6751.

133. Jayaraman A, Wood TK. Bacterial quorum sensing: signals, circuits, and implications for biofilms and disease. Ann Rev Biomed Eng. 2008;10:145-167.

134. Barthold SW, Hodzic E, Imai DM, Feng S, Yang X, Luft BJ. Ineffectiveness of tigecycline against persistent Borrelia burgdorferi. Antimicrob Agents Chemother. 2010;54(2):643-651.
135. Yrjänäinen H, Hytönen J, Söderström KO, Oksi J, Hartiala K, Viljanen MK. Persistent joint swelling and Borrelia-specific antibodies in Borrelia garinii-infected mice after eradication of vegetative spirochetes with antibiotic treatment. Microbes Infect. 2006; 8(8):2044-2051.

136. Yrjänäinen H, Hytönen J, Song XY, Oksi J, Hartiala K, Viljanen MK. Anti-tumor necrosis factor-alpha treatment activates Borrelia burgdorferi spirochetes 4 weeks after ceftriaxone treatment in C3H/He mice. J Infect Dis. 2007;195(10):1489-1496.

137. Yrjänäinen H, Hytönen J, Hartiala P, Oski J, Viljanen MK: Persistence of borrelial DNA in the joints of Borrelia burgdorferi-infected mice after ceftriaxone treatment. APMIS. 2010;118(9):665-673.

138. Embers ME, Barthold SW, Borda JT, et al. Persistence of Borrelia burgdorferi in rhesus macaques following antibiotic treatment of disseminated infection. PLoS One. 2012;7(1):e29914.

139. Klempner MS, Hu LT, Evans J, et al. Two controlled trials of antibiotic treatment in patients with persistent symptoms and a history of Lyme disease. N Engl J Med. 2001;345(2):85-92.

140. Wormser G, Schwartz I. Antibiotic treatment of animals infected with Borrelia burgdorferi. Clin Microbiol Rev. 2009;22(3):387-395.

141. Bockenstedt LK, Mao J, Hodzic E, Barthold SW, Fish D. Detection of attenuated, noninfectious spirochetes in Borrelia burgdorferiinfected mice after antibiotic treatment. J Infect Dis. 2002; 186(10):1430-1437.

142. Hodzic E, Feng S, Holden K, Freet KJ, Barthold SW. Persistence of Borrelia burgdorferi following antibiotic treatment in mice. Anitimicrob Agents Chemother. 2008;52(5):1728-1736.

143. Straubinger RK, Summers BA, Chang YF, Appel MJ. Persistence of Borrelia burgdorferi in experimentally infected dogs after antibiotic treatment. J Clin Microbiol. 1997;35(1):111-116.

144. Krupp LB, Hyman LG, Grimson R, et al. Study and treatment of post Lyme disease (STOP-LD): a randomized double masked clinical trial. Neurology. 2003;60(12):1923-1930.

145. Fallon BA, Keilp JG, Corbera KM, et al. A randomized, placebocontrolled trial of repeated IV antibiotic therapy for Lyme encephalopathy. Neurology. 2008;70(13):992-1003.

146. Fallon BA, Petkova E, Keilp JG, Britton CB. A reappraisal of the US clinical trials of post-treatment lyme disease syndrome. Open Neurol J. 2012;6:79-87.

147. Delong AK, Blossom B, Maloney EL, Phillips SE. Antibiotic treatment of Lyme disease in patients with persistent symptoms: a biostatistical review of randomized, placebo-controlled clinical trials. Contemp Clin Trials. 2012;33(6):1132-1142.

148. Vudattu NK, Strle K, Steere AC, Drouin EE. Dysregulation of CD4+CD25hi+ T cells in the synovial fluid of patients with antibioticrefractory Lyme arthritis. Arthritis Rheum. Epub February 28, 2013.

149. Chandra A, Wormser GP, Klempner MS, et al. Anti-neural antibody reactivity in patients with a history of Lyme borreliosis and persistent symptoms. Brain Behav Immun. 2010;24(6):1018-1024.

150. Bockenstedt LK, Gonzalez DG, Haberman AM, Belperron AA. Spirochete antigens persist near cartilage after murine Lyme borreliosis therapy. J Clin Invest. 2012;122(7):2652-2660.
International Journal of General Medicine

\section{Publish your work in this journal}

The International Journal of General Medicine is an international, peer-reviewed open-access journal that focuses on general and internal medicine, pathogenesis, epidemiology, diagnosis, monitoring and treatment protocols. The journal is characterized by the rapid reporting of reviews, original research and clinical studies across all disease areas.
A key focus is the elucidation of disease processes and management protocols resulting in improved outcomes for the patient. The manuscript management system is completely online and includes a very quick and fair peer-review system. Visit http://www.dovepress.com/ testimonials.php to read real quotes from published authors. 